\title{
EPSILON Modelica library for thermal applications
}

\author{
Laurent Lachassagne ${ }^{1}$ Arnaud Colleoni ${ }^{1}$ Hervé Feral ${ }^{1}$ Nicolas Dolin ${ }^{1}$ \\ ${ }^{1}$ Epsilon Ingénierie, France, \{llachassagne, acolleoni,hferal, ndolin\} @epsilon-alcen.com
}

\begin{abstract}
This paper presents the Modelica library built by the French company "Epsilon Ingénierie" in order to provide system models of several technologies for thermal applications. The Epsilon library has its own structure for media definition, allowing simulation of two-phase phenomena in the library models. This library also includes several heat transfer technologies models such as heat exchangers, thermo-electric generators, heat pipes, loop heat pipes, etc... This paper presents two examples of system modeling with the Epsilon library using OpenModelica: a capillary pumped loop and a Fresnel solar plant.
\end{abstract}

Keywords:Modelica library, heat transfer, systems, medium, two-phase, solar

\section{Introduction}

The current trend in industry is to electrify and downsize gradually the mechanical and hydraulic technologies. This evolution can only succeed by managing the excessive heat that needs to be evacuated. As the thermal systems have to be more efficient using smaller exchange areas to meet industry needs, designing the thermal architecture of any system becomes more and more difficult with average heat transfer technologies. New promising technologies, such as two-phase heat transfer devices which are innovative heat transport systems with high efficiency, need to be studied and implemented in engineering phases. A variety of physical conditions, such as the working fluid, have also to be studied. And eventually, smart meters need to be integrated to be able to compare all the available solutions.

Under these circumstances, manufacturers and system designers need easy-to-use modeling tools in order to include all these new technologies inside global models, modify the physical conditions, and to assess their potentials. Epsilon has chosen Modelica to develop its own heat transfer technologies models, enriched by its background in spatial, aeronautic, and process thermal challenges over the years. The main objective is to use these models for any applications where global thermal management is needed, such as planes, district heating or power plants for example.

\section{EPSILON library}

The Epsilon library (Figure 1) includes two main subsections: "Media" where materials are defined and "Systems" where models are located. The other packages are "toolboxes" for users. They gather several useful components for system models and mostly inspired by Epsilon from the ModelicaStandard library, especially the FluidHeatFlow library. Thus, Epsilon library connectors design is the same as in the FluidHeatFlow library. The objective is to make all components of the Epsilon library compatible with components of the ModelicaStandard library and this connector design seems to be adapted to thermohydraulic modeling.

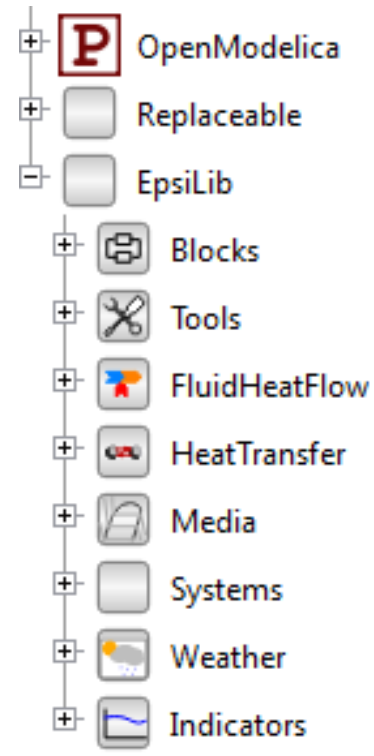

Figure 1.Structure of Epsilon library.

\section{1 "Media"}

In order to develop modular models, able to model phase change, where materials will be easily replaceable, Epsilon has decided to develop its own structure (Figure 2). This Media library is filled with material data and properties functions gathered by Epsilon over time. All materials (solids, fluids or gases) are called the same way: EspiLib.Media.Name. Phase.Temperature dependence (only for fluids).Type of laws.Properties functions. This makes easier the 
change of material in the studied models by modifying Name.

Regarding to fluids, models need only mass enthalpy and pressure as inlet variables. Temperature and vapor quality are computed inside fluid model. This way twophase flows can be managed in systems models, such as the Capillary Pumped Loop presented in section 3.

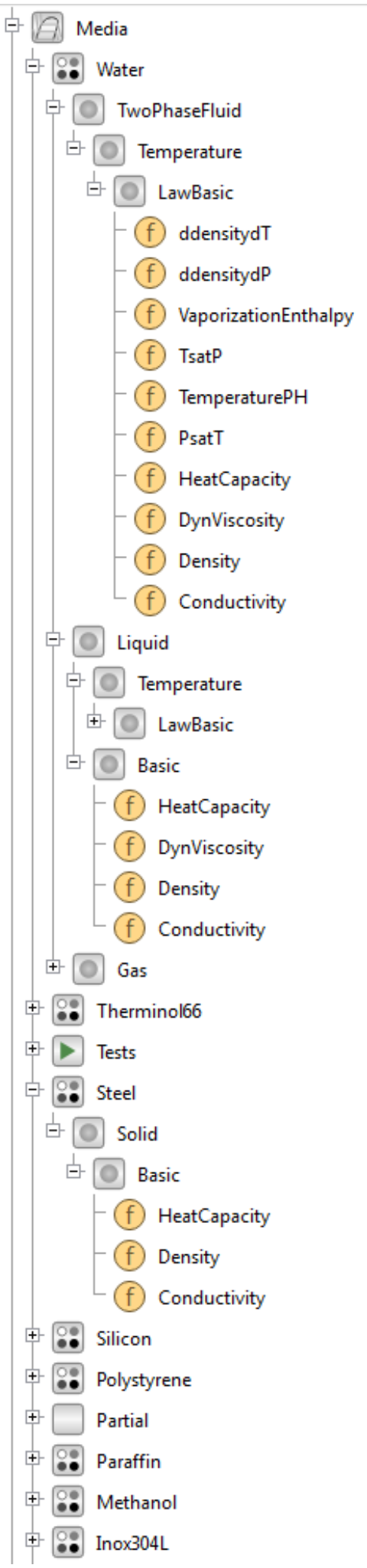

Figure 2.Structure of Epsilon "Media" library
The user can also choose to work with only one fluid state, by choosing "Liquid" or "Gas" instead of "TwoPhase" in the medium call Phase, to avoid nonlinearity or to use lightest models. For the moment Epsilon has not encountered applications with multicomponent mixture media.

\section{2 "Systems"}

The Epsilon "Systems" library (Figure 3) is divided into several packages depending on the technical applications of thermal management Epsilon has already encountered and simulated. "ThermalStorage" contains Phase Change Materials models. "Solar" includes models and sub-models for designing solar power plant as the Fresnel solar plant described in section 4. "HeatExchanger" gathers different models of heat exchangers, evaporators and condensers. "Electrical" contains Thermo-electric Generators models (such as Peltier cells). "Diphasic"gathers systems where two-phase fluids rule, such as heat pipes, loop heat pipes, heat pumps, etc... Eventually, "Building" package includes models for buildings energy management. These packages are not exhaustive and the Epsilon library is defined to be filled over time with applications coming from Epsilon expertise or client needs.

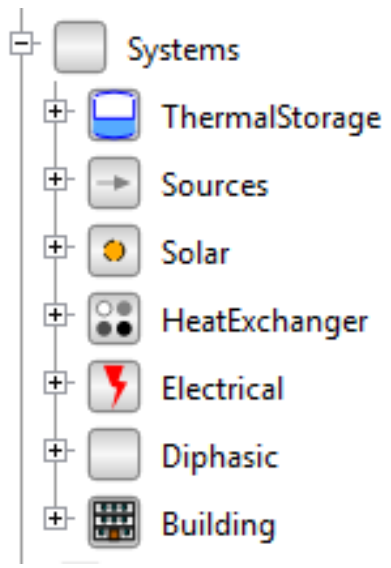

Figure 3.Structure of Epsilon "Systems"library.

\subsection{Implementing indicators}

When designing a thermal system, modeling has to supply answers to help choose between several configurations. To do so, several smart meters have to be included. Based on the "extends" possibilities of Modelica, the creation and integration of smart meters in system modeling is simplified.

Hence, a Modelica block has been created, containing the necessary equations to calculate costs at each time step with the following parameters:

- P0, initial cost of purchase

- P1Active, a Boolean when using P1, representing the cost of running energy

- $\quad \mathrm{P} 2$, maintenance cost 
- TimePeriod, for the maintenance time frequency

- $\quad$ P3, renewal facilities cost

To integrate a cost in a model, one only need to call the cost block "extends CostBlock $(\mathrm{P} 0=\mathrm{xx}, \mathrm{P} 1$ Active $=$ true, $\mathrm{P} 2=\mathrm{xx}, \mathrm{P} 3=\mathrm{xx}$ )" and to add an equation relative to $\mathrm{P} 1$. Moreover, a small icon with the Euro symbol will be added on the diagram view, allowing for a connection of the cost of each component to be treated in an economic model (as illustrated in figure 17).

Eventually, the generic structure of this meter makes it easy to create other indicators such as, $\mathrm{CO} 2$ generated, size, mass, footprint ... Hence, models developed in the Modelica Library can support simulations over multiple time scales: seconds to minutes for local dynamics/controls studies and days or years for overall economic value propositions studies. An example using these cost indicators is given in section 4 of this paper concerning modeling of a solar Fresnel power plant.

\section{Example: Capillary Pumped Loop model}

A first example of using the Epsilon library is the model of a complex innovative system: a capillary pumped loop. This system is mostly used to transfer heat from sources with high heat fluxes densities to a cold source. It was first developed around fifty years ago for space applications (Stenger, 1966) to transfer heat from dissipating cells to solar panels. For around ten years, these systems are also used for terrestrial applications (railway, planes) such as power electronics cooling (Vasiliev et al, 2009).

\subsection{Principle}

Capillary pumped loop (CPL) or Loop Heat pipes (LHP) are two-phase devices based upon the heat pipe working principle (Maydanik, 2004). The phase change of a pure fluid is used to transfer heat from the hot spot (evaporator) to the cold source (condenser). A porous media is inserted inside the evaporator to act like a pump for the fluid. The fluid flows in the loop due to combination of capillary pumping of liquid inside the porous wick and evaporation at the top of the wick. Liquid and vapor flow in separated lines between evaporator and condenser. A reservoir is added to the system to ensure that the evaporator wick will always be fed with enough liquid. The position of the reservoir determines the kind of loop and can impact the system behavior (Figure 4).

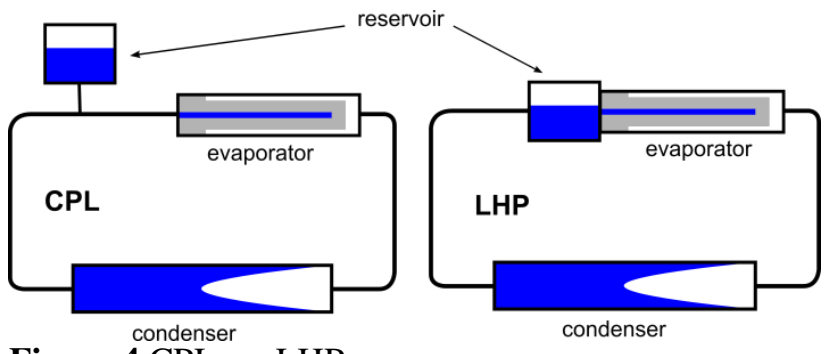

Figure 4.CPL vs. LHP.

The device used for this study is a particular kind of CPL: the capillary pumped loop for integrated power (CPLIP) developed by the Belgian company "Euro Heat Pipe". Its particularity is the reservoir position, which is located above the evaporator (Figure 5). Then gravity has an influence on reservoir/evaporator coupling, making this design halfway between CPL and LHP. This system has been tested for a terrestrial application and results are available in literature (Lachassagne et al, 2012). Epsilon society has developed and validated a Modelica system model of this device.

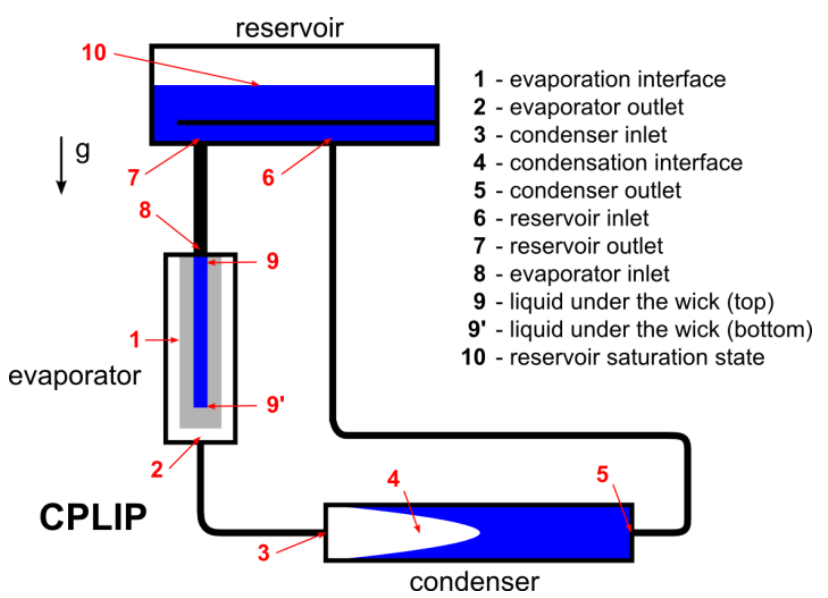

Figure 5.View of a Capillary Pumped Loop for Integrated Power(Lachassagneet al, 2012).

\subsection{Elementary cell}

The fluid generic volume (Figure 6) is the key component of Epsilon two-phase and one-phase device models. This "generic pipe" model is fitted with two fluid connectors (inlet and outlet) and one heat connector (heat exchange through the volume frontier). Variables exchanged by the "flowPorts" are mass enthalpy, mass flow, enthalpy flow and pressure. The variables exchanged by the "heatPort" are heat flow and temperature.

This elementary model has been tested using fluids of Epsilon library "Media" with a set of boundary conditions (Figure 7). It works both for one-phase and two-phase fluid flows. Flow change of direction is also possible. Several heat transfer and pressure losses correlations are available in the Epsilon library package "Tools" and can be chosen by the user. 


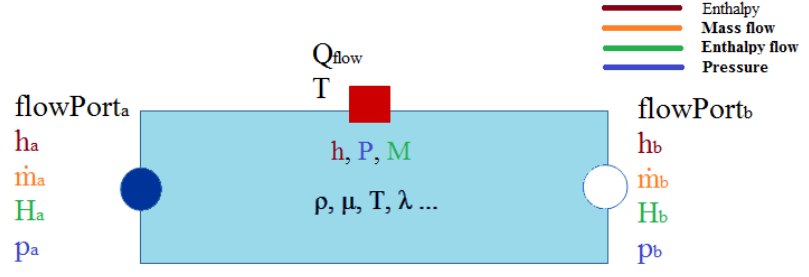

Figure 6.View of the elementary fluid volume variables.

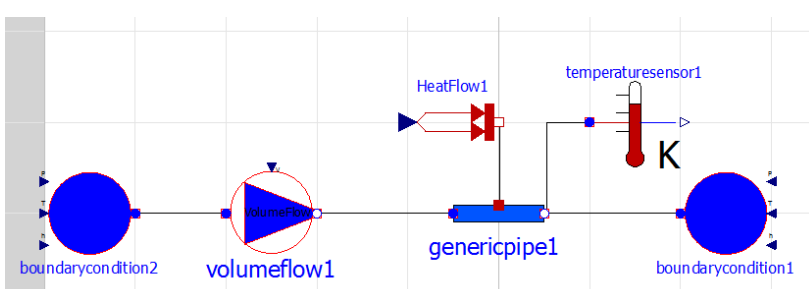

Figure 7.Test model of the elementary fluid volume "genericpipe" of the Epsilon library.

\subsection{CPL system Model}

By connecting several components of the Epsilon library, a complete CPLIP system model can be developed (Figure 8). According to the structure of Espilon media library, this model allows to change working fluid and materials with only one clic. Loop geometry parameters and heat transfer correlations can also be changed by the users.

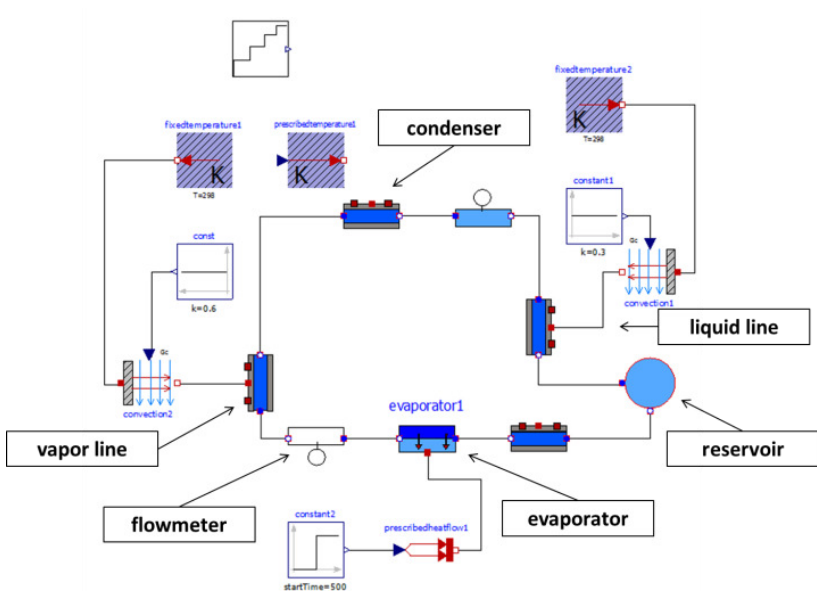

Figure 8.Test model of the CPLIP in the Epsilon library.

\subsection{Validation}

This model has been validated at steady-state by comparing with literature results (Lachassagne et al, 2012). These results were experimental data of a CPLIP test bench with ethanol as working fluid. Two kinds of models have been tested: one with a "complex" evaporator with many thermal and fluid couplings and the other "simplified" with only one coupling for the evaporation interface. On Figure 9 and Figure 10, dots stand for experiments results, dotted lines stand for the simplified evaporator model and plain lines stand for the complex evaporator models. It appears that both model fit the experiments results well, with little more precision for the complex evaporator model. The error remains greater for the hydraulic variables than for the thermal ones, which is still acceptable considering the great instabilities due to condensation in these systems.

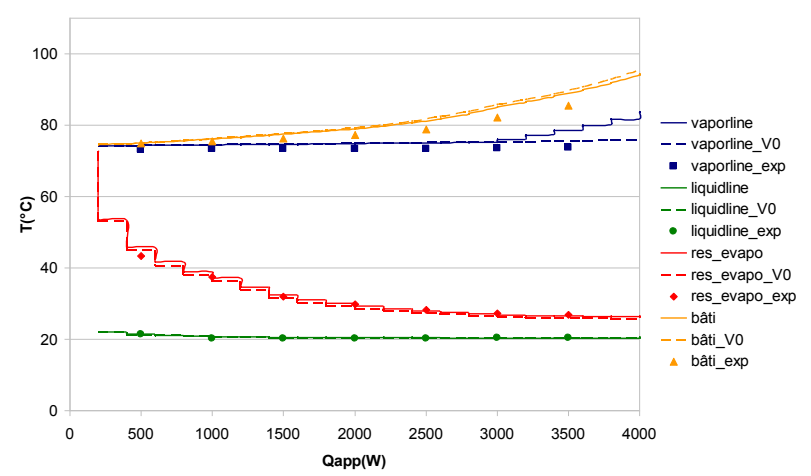

Figure 9.Temperatures vs. Heat power applied at the CPLIP evaporator.

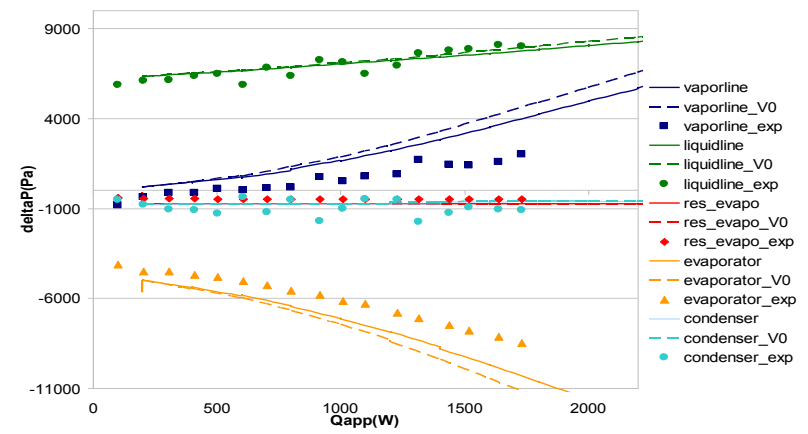

Figure 10.Pressure losses in the CPLIP components vs. Heat power applied at the CPLIP evaporator.

After comparing efficiency of these two CPL models, the last tests performed were numerical tests. Figure 11 shows the simulation duration function of number of elementary cell in the condenser. The objective of these tests was to assess the numerical reliability of the model not only for different complexity (two kinds of evaporator), but also for different model sizes (condenser discretization). Blue line stands for tests of the complex evaporator model and yellow line stands for the simplified evaporator model. Dots appearing on the abscissa axis represent a simulation crash for the corresponding number of condenser cells. The simplified model shows a quadratic behavior whereas complex evaporator model seems to have an exponential increasing of simulation duration with the condenser discretization. It also appears that complex model has many simulation crashes contrary to simplified one. Tests have also shown that the stability of the complex CPL model will be increased if the user 
is particularly careful of the boundary and start conditions of the model.

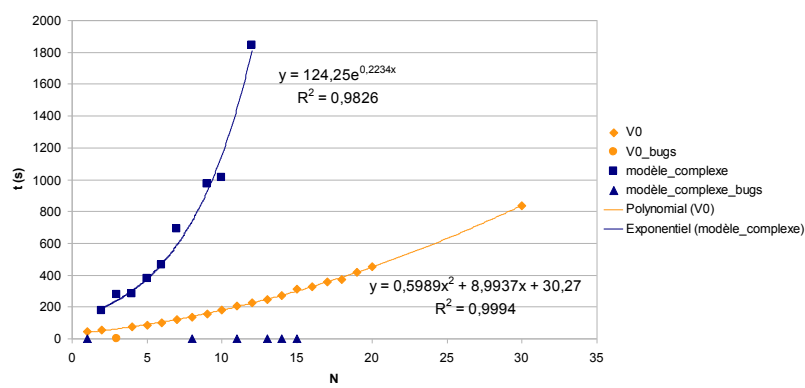

Figure 11. Simulation duration vs. CPLIP condenser cellsnumber.

It remains hard to explain this numerical behavior because of complexity of these kinds of models couplings. It is well-known that phase-change modeling leads to large discontinuities in fluid properties and then numerical issues. This will be investigated by Epsilon in the future, based on literature analysis (Bonilla et al, 2012). The fluid flow connector design can also be discussed. Epsilon has chosen to use the Modelica FluidHeatFlow connector design, as the Fluid library was not compatible with OpenModelica when the library development started, but the use of stream connectors, (Franke et al, 2009) which seems more robust, will be investigated for the future versions of Epsilon library.

To conclude, the interest for Epsilon of using Modelica for this kind of modeling is its modularity. It is really easy to have many levels of complexity for the system models and the user can choose what fits better with his objectives: more precision but less stability or less precision but more stability and short simulation durations.

\section{Example: Fresnel solar power plant}

A second example of using the Epsilon library is the model of a solar power plant.

\subsection{Principle}

Fresnel solar power plants (Figure 12) are linear thermal solar concentrators formed by an assembly of flat mirrors named "compact linear reflectors". Each reflector can spin according to sun location in order to reflect and concentrate sunbeams to one or more fixed receiver pipes. The fluid flowing through these pipes can then turn into vapor up to $500^{\circ} \mathrm{C}$. This vapor is available for industrial process or electricity generation for instance.

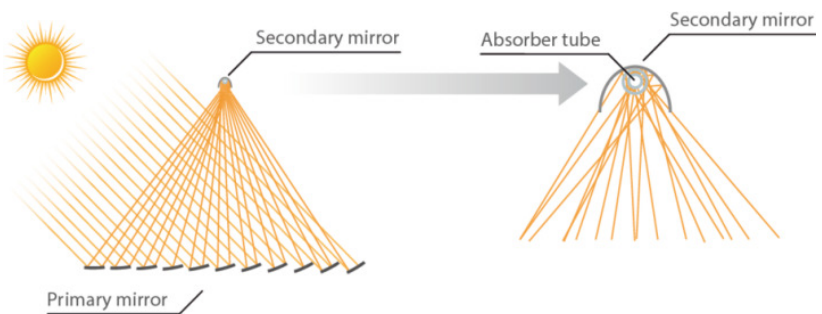

Figure 12.Linear Fresnel solar power plant principle.

Some studies about Fresnel solar power plants propose modeling of reflectors behavior (Pino et al, 2013). One study in particular has been performed using Modelica in order to simulate working points of the Fresnel solar power plant developed by Alsolen society (Rodat et al, 2014). This model still suffers some limitations, such as no storage modeling or also calling an external simulation code for mirrors modeling.

\subsection{Components}

\subsubsection{Receiver}

The power plant receiver has been developed using the elementary fluid volume described in Figure 6. The power plant receiver is subjected to three major thermal phenomena: solar heat flux absorption, radiations to environment and convection losses. These phenomena appear in the receiver detailed model developed by Epsilon in its library (Figure 13).

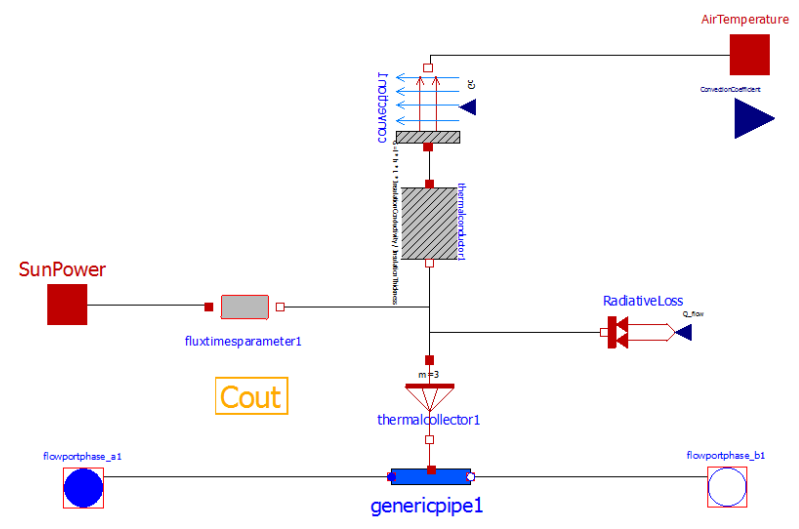

Figure 13.Receiver Modelica model structure.

The receiver component (Figure 14) is fitted with six ports:

- two fluid ports,

- one "heatport" for air temperature and one real port for convection coefficient, both depending on weather conditions,

- one "heatport" for received solar heat flux,

- one real port "Cost" for receiver cost transmission to global models.

Like all Epsilon library components, this receiver has been validated by simple test models. 


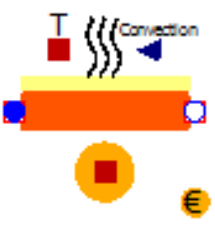

Figure 14.Receiver component design in Epsilon library.

\subsubsection{Mirrors}

A component describing optical behavior of a Fresnel mirror has been developed thanks to literature studies (Pino et al, 2013). This component can take into account the receiver shade on the mirrors field and the shade of mirrors to each other. This component appears in Figure 15 and is made of:

1. Weather data.

2. Solar angle calculation

3. Fresnel mirror.

4. Shade calculation.

5. Reflected solar heat flux.

6. Mirrors field cost calculation.

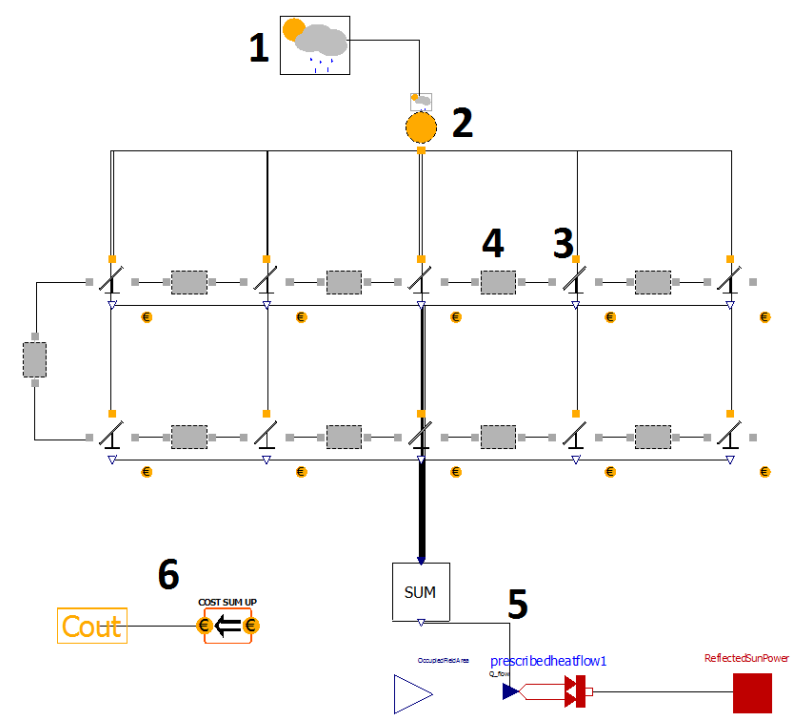

Figure 15.Mirror field assembly modeling.

\subsection{Solar power plant model}

The Fresnel solar power plant of this study is similar to the one has been developed by Alsolen company (Figure 16). Its features are:

- A $1000 \mathrm{~m}^{2}$ solar field,

- Therminol66 as working fluid,

- rock-bed thermal storage,

- a secondary heat loop by organic Rankine cycle.

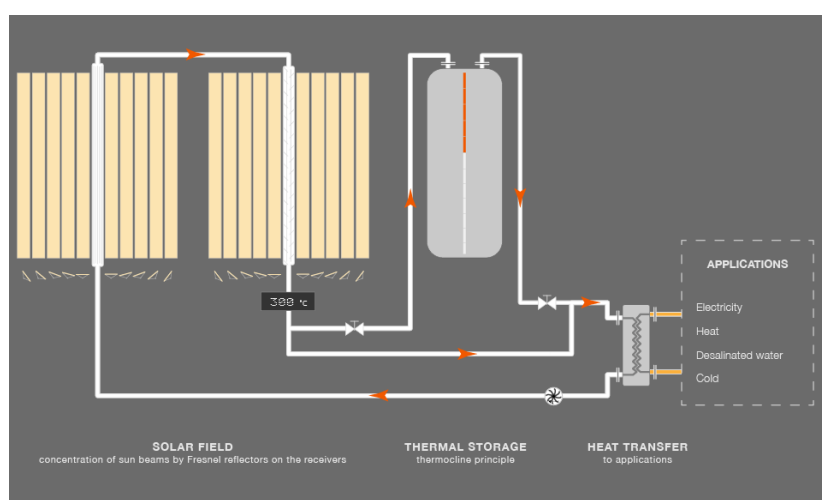

Figure 16.Linear Fresnel solar power plant of Alsolen company.

One main hypothesis has been made in the Espilon modeling of this plant (Figure 17): heat absorbed by the receiver working fluid is totally exchanged to the secondary loop which is currently not taken into account in the global model.

The components of the solar power plant are then:

1. Weather data, using classical weather files from building codes.

2. Solar receiver.

3. Fresnel mirrors field.

4. Thermocline thermal storage.

5. Mass flow rate regulation.

6. Total cost calculation.

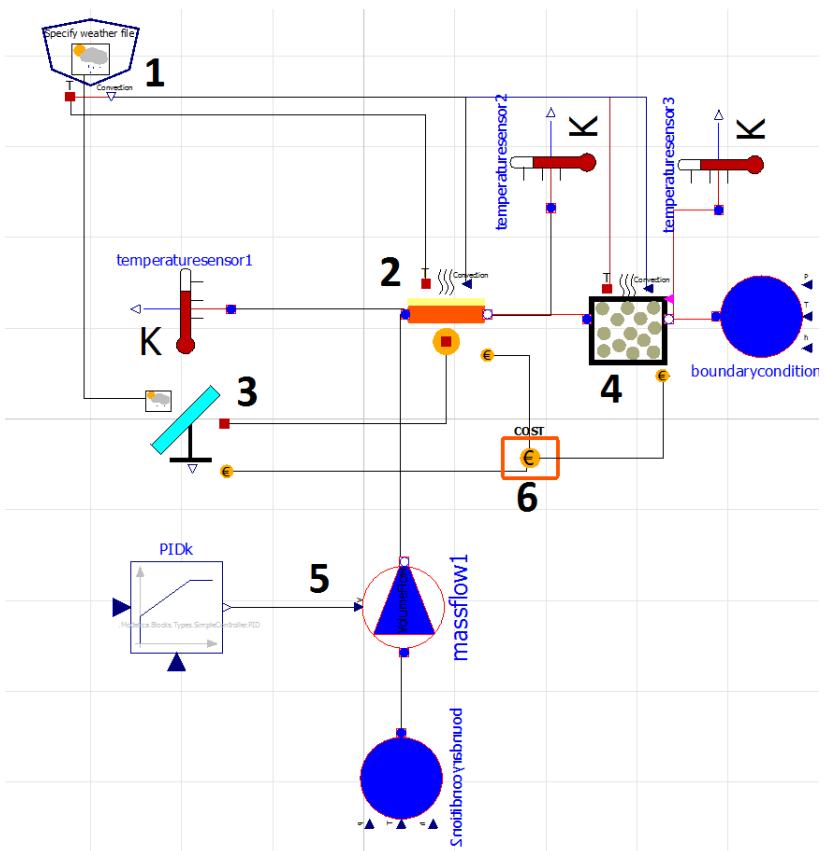

Figure 17.Epsilon Modelica model of the Alsolen Fresnel solar power plant. 


\subsection{Results}

The solar power plant has first been tested for three different locations in France (Table 1): Rouen (north of France), Toulouse (south of France) and Perpignan (extreme south of France).

Table 1.Solar power plant efficiency at three locations.

\begin{tabular}{|c|c|c|c|}
\hline location & Rouen & Toulouse & Perpignan \\
\hline $\begin{array}{l}\text { Solar resource } \\
(\mathrm{kWh} / \mathrm{m} 2 / \text { year })\end{array}$ & 905 & 1261 & 1441 \\
\hline $\begin{array}{l}\text { Reflected heat flux } \\
(\mathrm{kWh} / \mathrm{m} 2 / \text { year })\end{array}$ & 733 & 1033 & 1188 \\
\hline Optical efficiency & 0.81 & 0.82 & 0.82 \\
\hline $\begin{array}{l}\text { Absorbed heat flux } \\
(\mathrm{kWh} / \mathrm{m} 2 / \text { year })\end{array}$ & 436 & 661 & 772 \\
\hline Thermal efficiency & 0.59 & 0.64 & 0.65 \\
\hline $\begin{array}{l}\text { Cost / exergy } \\
(€ / k W h)\end{array}$ & 1.26 & 0.88 & 0.75 \\
\hline
\end{tabular}

Those first results allow checking the order of magnitudes obtained. Logically, Rouen is less favorable than Perpignan for the implantation of such central, decreasing the absorbed heat flux and the thermal efficiency (as the external temperature is lower). Eventually, the order of magnitude of the cost/exergy is realistic, with $75 \mathrm{cts}$ per $\mathrm{kWh}$, based on an hypothesis on 20 years funding (Nixon et al. 2012).

The Epsilon Modelica model of the solar power plant has also allowed to test the impact of spacing arrangement of mirrors on the plant efficiency (Table 2) and the cost/exergy.

Table 2.Solar power plant efficiency function of mirror spacing arrangement.

\begin{tabular}{|l|c|c|c|c|c|}
\hline $\begin{array}{l}\text { mirrors spacing } \\
\text { / mirrors width }\end{array}$ & 0 & 0.5 & 1 & 2 & 3 \\
\hline $\begin{array}{l}\text { Solar resource } \\
\text { (kWh/m2/ year) }\end{array}$ & 1261 & 1261 & 1261 & 1261 & 1261 \\
\hline $\begin{array}{l}\text { Reflected heat } \\
\text { flux (kWh/m2/ } \\
\text { year) }\end{array}$ & 901 & 1033 & 1056 & 1050 & 1030 \\
\hline $\begin{array}{l}\text { Optical } \\
\text { efficiency }\end{array}$ & 0.71 & 0.82 & 0.84 & 0.83 & 0.82 \\
\hline $\begin{array}{l}\text { Absorbed heat } \\
\text { flux (kWh/m2/ } \\
\text { year) }\end{array}$ & 560 & 661 & 678 & 664 & 642 \\
\hline $\begin{array}{l}\text { Thermal } \\
\text { efficiency }\end{array}$ & 0.62 & 0.64 & 0.64 & 0.63 & 0.62 \\
\hline $\begin{array}{l}\text { Cost / exergy } \\
\text { (€/kWh) }\end{array}$ & 0.85 & 0.88 & 0.99 & 1.32 & 1.59 \\
\hline
\end{tabular}

The spacing arrangement of mirrors is optimal when equal to the mirror width, when looking at the reflected heat flux. A smaller spacing arrangement creates shadowing between mirrors whereas a bigger spacing implies optical losses due to the angular position of mirrors to aim at the receiver.

The cost/exergy analysis gives a different result, where the optimal spacing between mirrors should be null, to minimize the ground size occupied (and so its cost). However, this solution is unrealistic since for maintenance and cleaning reasons, it is necessary to be able to circulate between the mirrors.

\section{Conclusion}

Epsilon has developed its own library of thermal solutions modeling with Modelica. This library is based upon a proper structure with media calculation allowing to simulate phase change phenomena well as integrating indicators (such as cost calculation) in global system models. Some models have already been developed and validated, such as capillary pumped loop model. This library provides several kinds of components which can be used for global system modeling, such as power plant modeling. Epsilon will continue to add new components for thermal control with the maximum return of experience available.

\section{References}

Yuri F. Maydanik, Loop Heat Pipes, Applied Thermal Engineering, No 25, pp. 635-657, 2004.

Laurent Lachassagne, Vincent Ayel, Cyril Romestant and Yves Bertin. Experimental study of capillary pumped loop for integrated power in gravity field.Applied Thermal Engineering, No 35, pp. 166-176, 2012.

doi:10.1016/j.applthermaleng.2011.10.019

F.J. Stenger, Experimental Feasibility Study of Water-filled Capillary-pumpedHeat-transfer Loop, NASA TM X-1310, Lewis Research Center, Cleveland, OH, 1966.

Leonid Vasiliev, David Lossouarn, Cyril Romestant, Alain Alexandre, Yves Bertin, Yauheni Piatsiushyk and Vladimir Romanenkov. Loop heat pipe for cooling of high-power electronic components. International Journal of Heat and Mass Transfer. No 52, pp. 301-308, 2009.

J. Bonilla et al. Chattering in dynamic mathematical twophase flow models, Applied Mathematical Modelling. No 36(5), pp. 2067-2081, 2012.

doi:10.1016/j.apm.2011.08.013

R. Frankeet al. Stream Connectors - an Extension of Modelica for Device-Oriented Modeling of Convective Transport Phenomena, Proc. 7th International Modelica Conference, Como, Italy, Sep. 20-22, 2009, pp. 108-121.

F. J. Pino, R. Caro, F. Posa and J. Guerra.Experimental validation of an optical and thermal model of a linear Fresnel collector system.Applied Thermal Engineering, No 50, pp. 1463-1471, 2013. 
S. Rodat, J. V. D. Souza, S. Thebault, V. Vuillerme and N. Dupassieux. Dynamic simulation of Fresnel solar power plant.Energy Procedia, No 49, pp. 1501-1510, 2014.

J.D. Nixon and A. Davies, Cost-exergyoptimisation of linear Fresnel reflector.Solar EnergyNo 86, pp. 147-156, 2012. 